\title{
Characterization of Momordica charantia Ussing FT-IR Spectroscopy
}

\author{
Attila KESERU ${ }^{1}$, Luisa ANDRONIE2 ${ }^{*}$, Ioana POP ${ }^{1}$, Ancuta ROTARU ${ }^{2}$, Danut MANIUTIU ${ }^{1}$, Aurelia \\ COROIAN $^{2}$, Camelia RADUCU ${ }^{2}$ \\ ${ }^{1}$ Faculty of Horticulture, University of Agricultural Sciences and Veterinary Medicine, Cluj-Napoca, \\ Romania \\ ${ }^{2}$ Faculty of Animal Science and Biotechnology, University of Agricultural Sciences and Veterinary \\ Medicine, Cluj-Napoca, Romania \\ *)Corresponding author, e-mail: andronie_luisa@yahoo.com
}

BulletinUASVM Horticulture 73(2) / 2016

Print ISSN 1843-5254, Electronic ISSN 1843-5394

DOI:10.15835/buasvmcn-hort:12161

\begin{abstract}
Momordica charantia (bitter melon) belongs to the family of Cucurbitaceae, a climbing vine which is commonly seen growing on walls and shrubs in the tropics. To demonstrate the result of studies which shows that the plant used as stomachic, carminative, tonic, antipyretic, antidiabetic, in rheumatoid arthritis and gout, the present investigation was carried to characterized a principal components of plant using FT-IR technique.
\end{abstract}

Keywords: FT-IR, medicinal properties, Momordica charantia

\section{Introduction}

Momordica charantia (Bitter Melon), a tropical vegetable, is a common food in Indian cusine and it is used extensively in folk medicine as a remedy for diabetes. The major parts used are leaves, fruits and flowers. Bitter melon has been used in various Asian traditional medicines for a long time. Leaves are simple; usually palmately 5-7 lobed, tendrils unbranched or 2 branched. The herbaceous, tendril bearing, vine grows to $5 \mathrm{~m}$. It bears simple, alternate leaves 4-12 $\mathrm{cm}$ across, with 3-7 deeply separated lobes. The main constituents of $M$. charantia are alkaloids, charantin, momordicin, ascorbic acid, phenol and protein (Sathish et al. 2010).

The fruit has claimed to contain charantin, steroidal saponin, momordicosides, carbohydrate, mineral matters, ascorbic acid, alkaloids, glucoside (Oragwa, 2013). The anticancerous and antileukemic activity of Momordica charantia against numerous cell lines including liver cancer, human leukemia melanoma and solid sarcomas have also been documented (Zhu, et al. 1990).
Most recent researches on the plant show that it has ability to inhibit the enzyme guanylate cyclase that is thought to be associated with psoriasis, leukemia and tumor pathogenesis (Grover et al. 2004), (Takemoto et al.1983). Crude extracts of the fruit of Momordica charantia possess antidiabetic activity (Rathi, 2002), (Guevara,1989) and many cucurbitane-type triterpenoids have been isolated from the fruits, (Hardman,1980), seeds (Rathi, 2002), (Okabe, 1982) and leaves of the plant.

\section{Aims and objectives}

The aim of this study was to identify the chemical compounds of Momordica charantia through FT- IR techniques. Vibrational spectral techniques, FT- IR, offer several advantages in the context of current research and using this techniques we can identify molecular components in the studied samples.

\section{Materials and methods}

For FT-IR measurements were performed in the absorbance with a spectrophotometer FT- 


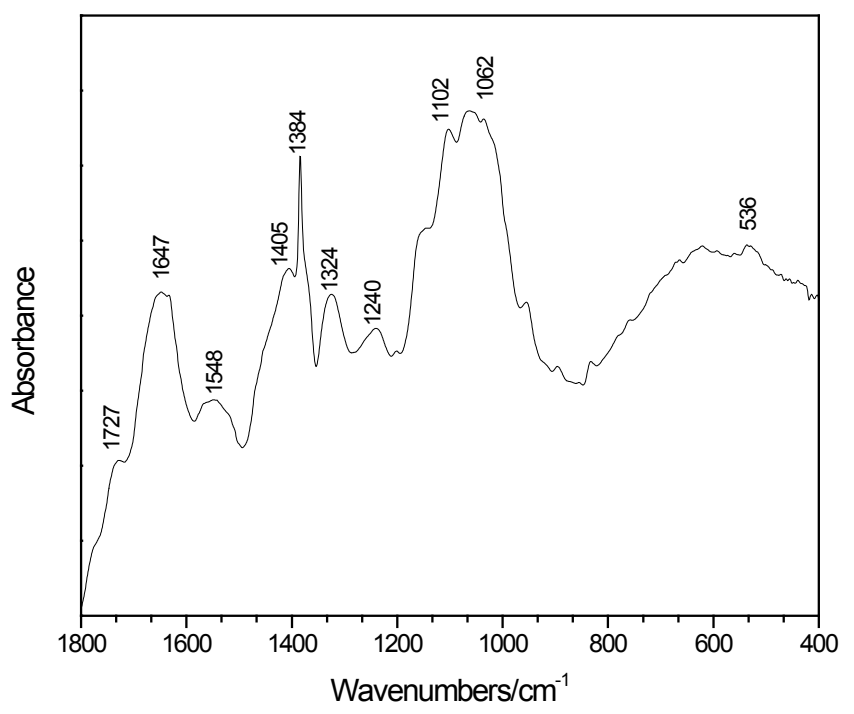

Fig. 1. FT-IR spectrum for Momordica charantia fruit

IR-4100 Jasco, using the $\mathrm{KBr}$ pellet technique. The spectra were obtained in the wavenumber range $265 \mathrm{~cm}^{-1}$. Spectral resolution was set at $4 \mathrm{~cm}^{-1}$ and all spectra were acquired over 256 scans. The sample was obtained from $0,003 \mathrm{~g}$ of dried plants (fruits) and ground.

\section{Results and discussion}

The vibrational fundamentals from the FTIR spectra, presented in Fig. 1. for Momordica charantia (fruits) were analyzed by comparing the experimental vibrational modes with the previous published data (Hlaing et al. 2005). In the "fringerprint" region the intense and broad absorption band characteristic of C-C, C-O and $\mathrm{C}-\mathrm{H}$ is present. The infrared spectra of Momordica charantia showed the presence of C-C stretching band at $1548 \mathrm{~cm}^{-1}$ and $1324 \mathrm{~cm}^{-1}, \mathrm{C}-0$ stretching band at $1240 \mathrm{~cm}^{-1}$.

The strong peaks at $1647 \mathrm{~cm}^{-1}$ were assigned to the $\mathrm{C}=\mathrm{C}$ stretching modes. The very weak band at $1102 \mathrm{~cm}^{-1}$ were assigned to the $\mathrm{C}-\mathrm{O}$ stretching and the same attribution is available for the weak peaks at $1062 \mathrm{~cm}^{-1}$. The in-plane bending modes of $\mathrm{C}-\mathrm{H}$ are attributed to the strong peak at 1384 $\mathrm{cm}^{-1}$ and in plane symmetrical bending of CCC is presence at $536 \mathrm{~cm}^{-1}$.

\section{Conclusion}

Using vibrational spectroscopy, it was proven that we can identify key molecular components in the samples studied and their molecular structure. This study has contributed to the characterization and identification of compounds in M. charantia seeds.

\section{REFERENCES}

1. Guevara AP, Lim-Sylianco CY, Dayrit FM, Finch P (1989). Acyglucosyl sterols from Momordica charatia. Phytochemistry. 28:1721-1724.

2. Grover JK and Yadav SP (2004). Pharmacological actions and potential uses of Momordica charantia. A review J. Etanopharmacol. 93: 123-132.

3. Hardman R (1980). Recent advances in plants of pharmacological importance. Steroidal aspects, Egypt. J. Pharm. Sec. 21(12):169.

4. Hlaing S, Htin A (2005). Phytoehemical Studies OH Momordica spp. Linn, and Extraction and Isolation of Charantin from the fruit of M. charantia L, Jour. Myan. Acad. Arts \& Sc.

5. Okabe H, Miyahara Y, Yamauchi T (1982). Chem. Pharm. Bull. 30:3977- 3986.

6. Oragwa L, Olajide O, Efiom O, Okwute Simon K (2013). Didecanoate compound: Isolated from Momordica charantia Linn. seeds from Nigeria. Afr. J. Pure Appl. Chem. 7(11):375-381.

7. Rathi SS, Grover JK, Vats V (2002). The effect of Momordica charantia and Mucuna pruriens in experimental diabetes and their effect on key metabolic enzymes involved in carbohydrate metabolism.Phytother. Res. 16:236-243.

8. Takemoto DJ, Jilka C, Rockenbach S, Hughes JV (1983). Purification and Characterization of a cytostatic factor with anti viral activiy from the bitter melon. Prep. Biochem. 371-393.

9. Sathish KD, Vamshi S K, Yogeswaran P, Harani A, Sudhakar K (2010). International Journal of Pharmaceutical Sciences Review and Research 1.

10. Zhu ZJ, Zhong ZC, Luo ZY, Xiao ZY (1990). Studies on the active constituent of Momordica charantia. 25:898 - 903. 